\title{
Public policies based on scientific evidence: child road safety
}

\author{
Virginia Núñez-Samudio, M.D. ${ }^{a, b, c}$ and Iván Landires, M.D., ${ }^{a, c, d, e}$
}

a. Institute of Medical Sciences, Las Tablas, Panama.

b. Division of Epidemiology, Department of Public Health, Herrera Health Region, Ministry of Health, Panama.

c. National Research

System (Sistema

Nacional de

Investigación,

SNI), National

Secretariat of

Science, Technology and Innovation

(Secretaría

Nacional de

Ciencia, Tecnología

e Innovación,

SENACYT),

Panama.

d. Hospital Joaquín Pablo Franco Sayas, Los Santos Health Region, Ministry of Health, Panama.

e. Azuero University Regional Center (Centro Regional Universitario de Azuero, CRUA), Universidad de Panamá, Chitre, Herrera, Panama.

E-mail address:

Iván Landires, M.D.: ilandires@instituto

deciencias medicas.org

Funding:

None.

Conflict of interest:

None.

Received: 4-20-2019

Accepted: 10-20-2019

\begin{abstract}
Road traffic accidents are a global public health problem. In Latin America, the mortality rate among children due to road traffic accidents almost doubles the global average. We describe our experience formulating a public policy on child road safety in Panama, based on the scientific evidence produced by our research group. Moreover, we propose a model for public policy-making that may be used in other Latin American countries. It is a formulation vector that is part of the public policy-making cycle and entails identifying a public problem, conducting scientific research, publishing and disseminating scientific products for public policy-making with the participation of scientists, the civil society, and decision-makers by sharing spaces for dialog. Key words: public policy, evidence-based medicine, cars, safety measure, Panama.
\end{abstract}

http:/ / dx.doi.org/10.5546/ aap.2020.eng.e252

To cite: Núñez-Samudio V, Landires I. Public policies based on scientific evidence: child road safety. Arch Argent Pediatr 2020;118(3):e252-e257.

\section{INTRODUCTION}

Road traffic accidents are currently a global public health problem. According to the World Health Organization (WHO), globally they cause 1.35 millions of fatalities per year and are the first cause of death among children aged 5 to 14 years and young people aged 15 to 29 years. ${ }^{1}$ In Latin America, the mortality rate among children due to road traffic accidents almost doubles the global average. $^{2}$

Previously, this was considered a problem that concerned the transport sector; however, due to the high figures of victims, the health sector currently has an active global participation in the prevention and surveillance of road traffic accident fatalities and victims. It is important to make clear the determinants that play a critical role in the high rate of child mortality and disability that results from road traffic accidents. For instance, the benefits for the general population would increase if traffic conditions were safer or adequate public policies for the correct use of seat belts and child restraint systems (child safety seats for children traveling in cars) were established. ${ }^{3}$

Several studies have demonstrated that the correct installation and use of child restraint systems in cars reduces mortality in children younger than 1 year old by approximately $71 \%$, and by $54-80 \%$ in children aged 1 to 4 years. Moreover, child restraint systems prevent between $50 \%$ and $90 \%$ of all severe child injuries, including sequelae leading to disability. ${ }^{4-6}$

Even though there are international consensuses related to child restraint system regulations, they vary greatly from one country to the other, which is reflected in their annual child mortality rates due to road traffic accidents. A study conducted in 2016 by MAPFRE, based on data from several Latin American countries, showed that the mean annual child mortality rate due to road traffic accidents was 32 per million population, whereas in European Union countries that study reported 6 deceased children per million population; this means that, in Latin American countries, the mean annual child mortality rate due to road traffic accidents was up to 5.3 times higher than in the European Union. $^{7}$

According to a Latin American study ${ }^{8}$ the New Car Assessment Programme for Latin America and the Caribbean (Latin NCAP) has shown advances in updating the safety levels of the best-selling cars in the region. In 
the near future, all new cars sold in the region will have to comply with the highest score possible in order to protect child and adult safety in Latin America.

In a recent study, ${ }^{8}$ only 1 and 7 out of 48 assessed car models attained a 5-star protection level for child and adult passengers, respectively, which shows that there is still a long way to go in the improvement of safety technology for the users of new cars sold in Latin America. With these assessments, Latin NCAP has been promoting improvements in measures for child restraint system use in Latin America.

A recent Latin American study on the situation of in-car child safety, ${ }^{8}$ with data from 17 countries and based on a scoring system, analyzed the following outcome measures: child accident rate, legislation on child restraint systems, audit effectiveness, technical requirements of child restraint systems, awareness campaigns on child restraint systems, and child accident statistics available online. After the analysis, it is clear that in almost every Latin American country child accident mortality rates double, or more, those observed in North America and European countries, where more adequate laws on child road safety have been established.

This reveals a clear need for new public policies on child road safety in Latin America. According to the study data, there are different advances in the audit and legislation associated with child restraint systems. In particular, for example, most Latin American countries had weaknesses in laws related to the compulsory use of child restraint systems, and only three countries had laws and auditing strategies in force for the compliance of legislation which could be considered "complete" according to the assessment.

Audit only makes complete sense when there are no major deficiencies in legislation, which is not the case in most Latin American countries. In North America and in European countries with adequate road safety legislation, for a child restraint system to be sold, the manufacturer must be able to prove that their product can pass certain safety tests. Only three of the countries considered in a recent study (Brazil, Chile, and Puerto Rico) require compliance with some type of national or international technical regulation for products offered in the market. Moreover, according to such study, only four countries (Brazil, Puerto Rico, Mexico, and Uruguay) have national, permanent and specific campaigns for the promotion of child restraint system use.

Regarding online data availability, these are not obtained nor recorded in a comparable way by the different Latin American countries. In five of the studied countries, the required information is not available online. The aforementioned study has made the following recommendations: ${ }^{8}$ 1. Formulating and reviewing national laws to ensure the universal protection of children in cars. 2. Such laws must also require that all child restraint systems and seats comply with one of the available international technical regulations and that an adequate audit is conducted. 3. Adopting and/or updating a data collection and processing system based on international regulations. 4. Launching campaigns on in-car child vulnerability and the need for the correct use of child restraint systems.

Regarding the specific situation of road safety in Argentina, there is a need for a more robust legal framework on child restraint systems. ${ }^{8} \mathrm{~A}$ study on child and adolescent mortality due to road traffic accidents in Argentina, conducted by the National Road Safety Agency (Agencia Nacional de Seguridad Vial, ANSV), reported that $8 \%$ accounted for victims younger than 16 years. ${ }^{9}$ Decree $779 / 95$, which amends Road Traffic Act 24449, mandates the use of child restraint systems. ${ }^{9}$ However, each jurisdiction must adhere to the act for it to be effective within that region. Article 40 of the Decree reads as follows: " ${ }^{\prime}$ Children younger than 10 years must travel secured to the back seat of the car with an authorized child restraint system, according to their size and weight".

Moreover, technical requirements for in-car safety in Argentina are above the average of those set by Latin American and Caribbean countries. ${ }^{8}$ It is also worth noting that Argentina stands out for its work on road safety campaigns related to child restraint systems through the ANSV. ${ }^{8}$

Based on a study on the situation of child road safety conducted in Panama, ${ }^{10}$ our research group recently showed that deaths among children due to road traffic accidents were a public health problem, which after the first year of life and up to 14 years of age was the main cause of death after infections. According to that study, in Panama, between 2005 and 2012, a total of 10603 victims of road traffic accidents aged 0-14 years were recorded, out of which 213 were fatalities. Nevertheless, these figures only reflected the number of victims who died at the site of the accident; they may therefore be even higher, given 
that the WHO suggested defining deaths from road traffic accidents as those happening within 30 days after the event and as a consequence of the injuries suffered in the accident.

The study also reported that, in Panama, the mean annual child mortality rate due to road traffic accidents was 28 per million population, between 3 and 4 times higher than that of countries with adequate road safety regulations, such as Spain, and that children younger than 5 years were the group with the highest number of fatalities and also the highest percentage of case-fatality rate. ${ }^{10}$ Crashes of cars transporting children were the type of road accident that caused the highest number of victims $(68 \%)$, followed by running over pedestrian children (19\%), children transported in cars that overturned (9\%), and others $(4 \%)$, which suggested that a substantial majority -of at least $77 \%$ - of children who were road traffic accident victims in Panama were car passengers. ${ }^{10}$

The increased fatality in children younger than 5 years is probably due to the lack of legislation on the use of child restraint systems and the unavailability of better information and awareness campaigns. Based on the scientific evidence gathered from this study, in the short term, we were able to identify a public health problem affecting children; in the medium term, the possibility of adopting a new traffic public policy emerged; and in the long term, we expect a significant decrease in mortality and sequelae.

In Panama, Article 127 of Traffic Regulations sets out the requirement for child restraint system use only in children younger than 2 years who travel alone in the back seat of a car; ${ }^{8}$ based on the scientific evidence described above, it is therefore necessary to develop better public policies for child road safety.

\section{Formulation of road safety public policies based on scientific evidence}

The Republic of Panama has a state public policy on road safety, the National Plan for the Decade of Action for Road Safety 2011-2020, ${ }^{11}$ with the following goals: 1 ) Reduce by $15 \%$ the mortality rate per 100000 population by 2020; 2) Reduce by $43 \%$ the accident rate per 100000 population by 2020. The public policy cycle consists of three basic elements: formulation, implementation, and evaluation. ${ }^{12}$ Formulating or designing a public policy entails being able to detect a public problem and determine the best course of action to solve it. ${ }^{12}$
In this article, we share our recent experience of multisector collaborative work to formulate a public policy for child road safety based on the scientific evidence produced by our research group,$^{10}$ which suggests improving the existing state public policy by detecting a public problem (increased mortality rate due to road traffic accidents in Panamanian children) and proposing an adequate course of action to attempt to reduce such mortality (regulation on the use of child restraint systems for every child measuring less than $135 \mathrm{~cm}$ who travels in a car). Once the evidence was obtained and the study was published in a scientific journal, ${ }^{10}$ our research group from the Institute of Medical Sciences resolved to keep on working towards formulating better public policies on child road safety in Panama. To this end, civil society actors and decision makers from the government and legislative sectors were added.

The study results were presented in different scientific conferences and symposiums, as well as to the Panamanian Society of Pediatrics, scientific movements from Panama, government representatives, such as the director from the Land Transit and Transportation Authority (Autoridad de Tránsito y Transporte Terrestre, ATTT), and several deputies of Panama's National Assembly. Moreover, the study results were disseminated through Panama's media and on social media. Thanks to our lobbying, different actors from the civil society have joined us, such as selective transport drivers, foundations interested in road safety education, potential sellers of child restraint systems, and natural persons. We requested the floor during the plenary session of the National Assembly in order to present the scientific evidence supporting the proposal of designing a law on child road safety in Panama, which was written by a group of deputies with our scientific counseling and the help of participating representatives of the civil society.

These public policy formulation efforts produced results in March 2018, when the merged bills 491 and 510 were approved in third debate in Panama's National Assembly, ${ }^{13}$ which adopted road safety measures for minors in order to "establish the mandatory use of child safety seats (CSS), as a prevention and road safety measure for children measuring up to $135 \mathrm{~cm}$, who at all times must use child safety seats in accordance with their age, size, and weight when traveling in the back seat of a vehicle, with the purpose of protecting their physical integrity". 
To our knowledge, this is the first time that a public health policy formulation in Panama is based on a study of scientific evidence, conducted entirely in our country with Panamanian data and researchers, who identified a public health problem and proposed the improvement of a public policy based on a national law. In 2018, the WHO reported that the only countries in Latin America who had road safety laws with goals similar to those described above were Costa Rica, Chile, and Uruguay. ${ }^{1}$

This is an example of how research and scientific evidence produced in Latin American countries may influence public health policies. Many governments have recognized improving legislation with new and better public policies as a measure to mitigate risk factors for road traffic accidents ${ }^{1}$ and their associated mortality and disability rates. Nevertheless, it is important to acknowledge that legislations frequently have limitations since they are only the first step in prevention, given that many previous experiences have shown that simultaneous efforts should be made by manufacturers to improve the technology and technical standards of cars sold in the country ${ }^{14}$ and child restraint systems. ${ }^{8}$
At the same time, measures should be strengthened to allow the civil society to be mobilized to improve the access to child restraint systems by the less economically favored sectors of the population through discounts, coupons, gifts certificates, recycling and reuse programs, or free distribution directly, and maintain continuous educational programs to encourage their purchase and correct use. ${ }^{15}$ Compliance with legislation on the use of child restraint systems should also be promoted with an adequate audit. ${ }^{8}$ These last points are already being discussed and analyzed in roundtables regarding legislation on child road safety in Panama.

\section{DISCUSSION}

According to our experience and its analysis, Figure 1 suggests a model that allows scientists to actively participate in the formulation of public policies based on scientific evidence produced by themselves. This model shows a public policymaking vector that entails identifying a public problem and conducting scientific research, and publishing and disseminating scientific products for public policy-making with the participation of scientists, the civil society, and decision-makers.

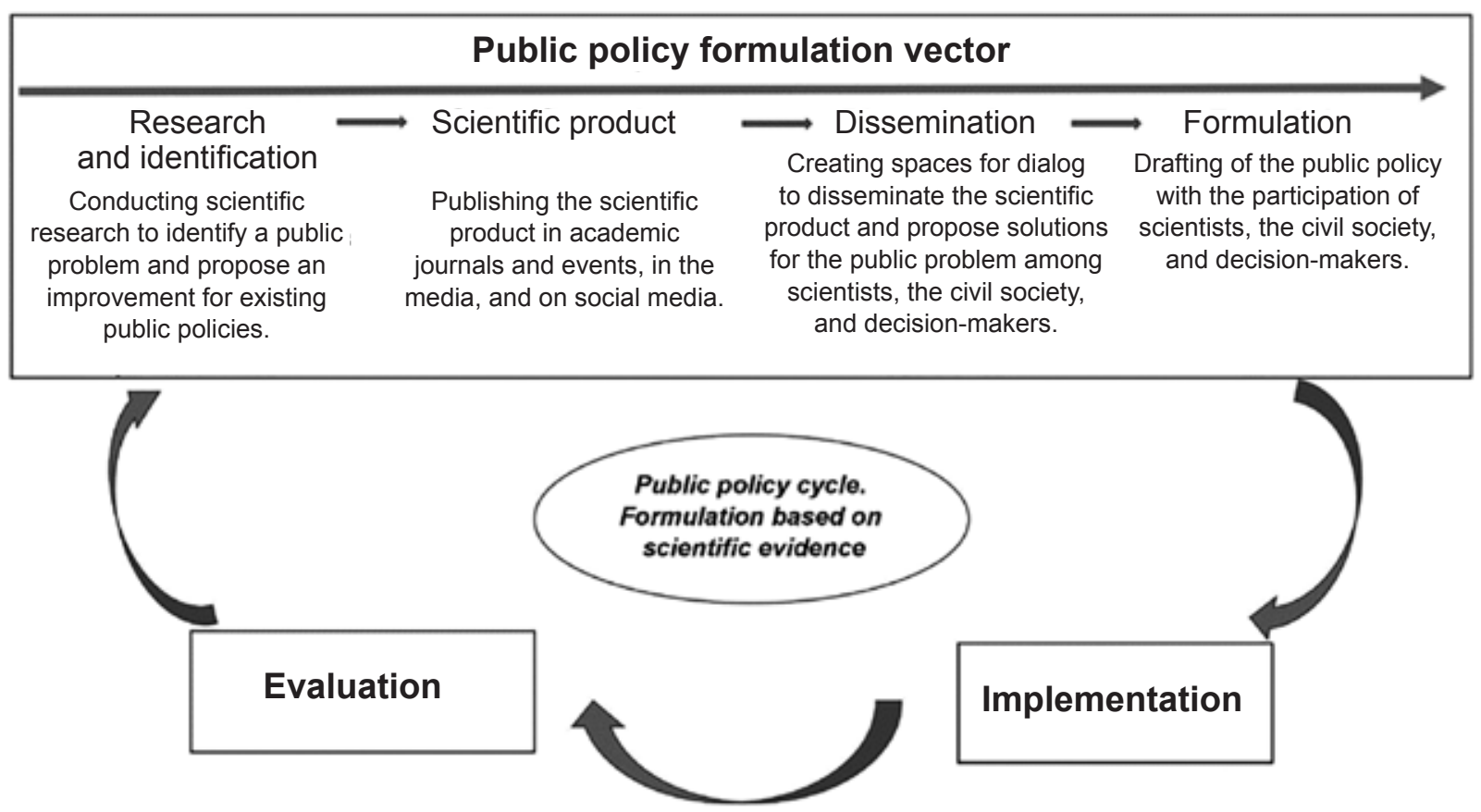


The formulation vector proposed in this article is part of the public policy cycle and has the potential to become a catalyst for public policymaking when scientists, the civil society and decision-makers share spaces for dialog.

Given its importance on global health, road safety has been included in the Sustainable Development Goals (SDGs) ${ }^{16}$ for 2030, specifically in the following: a) In SDG no. 3 regarding good health and well-being, in its target 3.6: "By 2020, halve the number of global deaths and injuries from road traffic accidents". b) In SDG no. 11 regarding sustainable cities and communities, in its target 11.2: "By 2030, provide access to safe, affordable, accessible and sustainable transport systems for all".

More and better public policies are needed to achieve the SDG targets regarding road safety; we therefore expect that our experience -as well as the model proposed in this article for public policy formulation based on scientific evidence-fosters the development, in other Latin American countries, of new studies and proposals effectively including the participation of scientists, the civil society, and decision-makers throughout the entire public policy cycle.

\section{Acknowledgments}

The authors would like to thank the National Research System (Sistema Nacional de Investigación, SNI) of the National Secretariat of Science, Technology and Innovation (Secretaría Nacional de Ciencia, Tecnología e Innovación, SENACYT) from Panama for their continued support in the public policy-making process based on scientific evidence produced by our research group.

\section{REFERENCES}

1. World Health Organization. Global status report on road safety 2018.Geneva: WHO; 2018. [Accessed on: February 26th, 2019]. Available at: https://www. who.int/ violence_ injury_prevention/road_safety_status/2018/en/.

2. Fundación FIA. Calles para la vida. Trayectos Seguros y Saludables para los niños de América Latina y el Caribe. Santiago, Chile: UNICEF/Save the Children/FIA Foundation; 2018. [Accessed on: February 26th, 2019]. Available at: https: / / www.unicef.org/ lac/media/2166/ file.

3. Banstola A, Mytton J. Cost-effectiveness of interventions to prevent road traffic injuries in low- and middle-income countries: A literature review. Traffic Inj Prev. 2017; 18(4):357-62.
4. Sauber-Schatz EK, West BA, Bergen G; Centers for Disease Control and Prevention (CDC). Vital signs: restraint use and motor vehicle occupant death rates among children aged 0-12 years - United States, 2002-2011. MMWR Morb Mortal Wkly Rep. 2014; 63(5):113-8.

5. Zaza S, Sleet DA, Thompson RS, Sosin DM, et al. Reviews of evidence regarding interventions to increase the use of child safety seats. Am J Prev Med. 2001; 21(4 Suppl):31-47.

6. Zhu M, Cummings P, Chu H, Cook LJ. Association of rear seat safety belt use with death in a traffic crash: a matched cohort study. Inj Prev. 2007; 13(3):183-5.

7. Ortega J, Monclús J, Gutiérrez A, Murciano M, et al. Dossier Fundación MAPFRE 2016 de Seguridad Vial Infantil en el automóvil en España y Latinoamérica: Sillitas infantiles. Madrid: Fundación MAPFRE; 2016. [Accessed on: February 26th, 2019]. Available at: https: / / sillasdecoche.fundacionmapfre.org/infantiles/images / Dossier-fundacion-mapfre-sri-2016_tcm725-240488.pdf.

8. Gallego Galeano R, De la Peña Mendoza S, Muñoz R, Taddia A, et al. Seguridad vial infantil: uso de los sistemas de retención. Análisis de la situación en América Latina y el Caribe. Washington, DC: BID / Fundación Mapfre; 2015. [Accessed on:September 26th, 2019]. Available at:https: / / publications.iadb.org / es/publicacion/ 15480 / seguridadvial-infantil-uso-de-los-sistemas-de-retencion-analisis-dela-situacion.

9. Argentina. Agencia Nacional deSeguridad Vial. Los chicos en el auto: ¿viajan seguros? [Accessed on: September 26th, 2019]. Available at: https://www.argentina.gob.ar / seguridadvial/viaje-sri.

10. Nuñez-Samudio V, Jaramillo-Morales J, Landires I. Prevalence and characteristics of child victims in motor vehicle collisions in Panama. Traffic Inj Prev. 2016; 17(4):391-3.

11. Organización Panamericana de la Salud. Plan Nacional Para el Decenio de Acción para la Seguridad Vial 2011-2020 de la República de Panamá. [Accessed on: February 26th, 2019]. Available at: https://www. who.int/roadsafety/ decade_of_action/plan/panama.pdf.

12. Knoepfel P, Larrue C, Varone F, Hill M. Public policy analysis. Bristol: Bristol University Press; 2007.

13. Proyectos de Ley 491 y 510 fusionados. Queadopta medidas de seguridad vial para menores deedad. Panamá: Asamblea Nacional de Panamá; 20 de marzo de 2017. [Accessed on: February 26th, 2019]. Available at:https: / / www.asamblea. gob.pa / APPS /SEG_LEGIS / PDF_SEG/PDF_SEG_2010/ PDF_SEG_2017/2017_P_491.pdf.

14. Furas A, Bidez M, Burke D, MerglK, et al. A Demonstration Project to Protect Child Road Users in a Latin American Country: Year 1 Engineering Assessment Status Report. 6th International Conference. Protection of Children in Cars. Munich, 4-5 December 2008. [Accessed on:September 26th, 2019]. Available at: https: / / www. researchgate.net/ publication $/ 265268532$.

15. Ehiri J, Ejere HOD, Magnussen L, Emusu D, et al. Interventions for promoting booster seat use in four to eight year olds travelling in motor vehicles. Cochrane Database Syst Rev. 2006; 25(1):CD004334.

16. Organización de las Naciones Unidas. Objetivos de Desarrollo Sostenible. [Accessed on: April 20th, 2019]. Available at: https:// www.un.org/ sustainable development/ es/objetivos-de-desarrollo-sostenible/. 